\title{
Artigo
}

\section{A DIALÉTICA DA MÁSCARA NEGRA: NEGO FUGIDO CONTRA O BLACKFACE}

\author{
THE BLACK MASK DIALETIC: \\ NEGO FUGIDO AGAINST BLACKFACE
}

LA DIALÉCTICA DE LA MÁSCARA DEL NEGRO:
NEGO FUGIDO CONTRA EL BLACKFACE

Monilson dos Santos Pinto

Monilson dos Santos Pinto Doutorando em Artes Cênicas pela Escola de Comunicações e Artes da Universidade de São Paulo. 


\section{Resumo}

Este artigo propõe um diálogo entre as expressões populares da cultura brasileira e o conhecimento hegemônico acadêmico por meio do teatro didático brechtiano, introduzindo reflexões acerca dos aspectos teatrais, corporais, visuais e musicais do Nego Fugido. A comunicação aponta para a necessidade de se pensar um teatro pautado em epistemologia da resistência negra e em estéticas quilombolas como possibilidades de criação cênica para grupos de teatro negro de periferia. A máscara negra da cultura popular e o blackface aparecem em oposição para revelar como elementos cênicos e aspectos teatrais dessas expressões populares são malcompreendidos, malbaratados e, muitas vezes, apropriados de forma insipiente por alguns encenadores e grupos de teatro contemporâneos.

Palavras-chave: Cultura popular, Bertolt Brecht, Teatro político, Blackface.

\section{Abstract}

This article proposes a dialogue between popular expressions of brazilian culture and the prevailing academic knowledge through Brechtian epic theater, introducing reflexions about theatrical, corporeal, visual and musical aspects of Nego Fugido. The comunication points to the necessity of conceiving a theater based on epistemology of black popular resistence and black comunitites aesthetics as possibilities of scenic creation to suburban black theater groups. The black mask of popular culture and the blackface appear in oposition to reveal how scenic elements and theatrical aspects of theses popular expressions are missunderstood, undermined and, many times, apropriated in an inscipient manner by stagers and contemporary theater groups.

Keywords: Popular culture, Bertolt Brecht, Political theatre, Blackface. 


\section{Resumen}

En este artículo se propone un diálogo entre las expresiones populares de la cultura brasileña y el conocimiento hegemónico académico a través del teatro brechtiano didáctico, introduciendo reflexiones sobre los aspectos teatrales, corporales, visuales y musicales del Nego Fugido. La comunicación apunta para la necesidad de pensar un teatro basado en epistemología de la resistencia negra y en estéticas de quilombos como posibilidades de creación escénica para grupos de teatro negro periféricos. La máscara negra de la cultura popular y el blackface aparecen en oposición para revelar cómo elementos escénicos y aspectos teatrales de estas expresiones populares son mal comprendidas despilfarrado $\mathrm{y}$, muchas veces, apropiados de manera imprudente por parte de algunos directores y grupos de teatro contemporáneos.

Palabras clave: Cultura popular, Bertolt Brecht, Teatro político, Blackface.

As águas calmas da Baía de Todos os Santos se agitam, tambores ecoam, gritos e lamentos se ouvem pelas ruas de terra de uma vila de pescadores... Ao pé dos atabaques, homens, mulheres e crianças de almas negras encobrem de fé seus corpos bronzes com uma mistura de óleo e carvão. Cicatrizes. Um mergulho no vazio, máscara preta e missa de corpo presente. Dois mundos, cara a cara! O tempo se perde e a batalha recomeça. As sendas que outrora cortavam o canavial e davam passagem ao avanço do sistema escravista agora são o cenário do Teatro das aparições do Nego Fugido: tocando, dançando e declamando em ladainhas, os moradores de Acupe incorporam seus deuses africanos, seus poderes, suas habilidades de guerreiros, seu senso de Justiça, seu espírito de luta, fazendo de si a imagem e semelhança de seus ancestrais para tecer o enredo de uma saga: a dos escravos que assumiram o poder na Colônia e subjugaram o rei de Portugal, escravizando-o, por sua vez, e contradizendo a história oficial do Brasil ao colocar o negro como protagonista da aquisição da sua liberdade (PINTO, 2014).

Foi a necessidade de refletir acerca da teatralidade, corporalidade, visualidade e musicalidade do Nego Fugido - em sua perspectiva estética e política - que me fez atravessar as ruínas da escravidão de Acupe. Em 2011, pintei 
meu rosto de carvão, vesti meu jaleco, meu chapéu de couro e minha saia de palha e fugi para São Paulo, um Nego Fugido querendo estudar artes cênicas.

No início da pesquisa de mestrado, fui convidado a discutir conhecimentos adquiridos nas práticas das expressões populares da cultura do Recôncavo baiano, no evento organizado pelo Núcleo de Artes Afro-brasileiras da Universidade de São Paulo (USP), possibilitando-me, logo de cara, vestir a carapuça do pesquisador. Intencionalmente, meu discurso emotivo revelava que o Nego Fugido era mais do que um objeto de pesquisa. Falar sobre o grupo era falar da minha vida, de pertencimento, da construção da minha identidade e da comunidade de Acupe, embora eu soubesse que estava em um espaço que exigia certo distanciamento, diante de um público que esperava o discurso de um pesquisador e não de um brincador emocionado pelas descobertas que fazia sobre si.

Após alguns minutos de conversa, passei a comentar sobre o uso da anilina, do carvão e do óleo de cozinha na produção da maquiagem que caracteriza os integrantes como negros e escravos, pensando esse processo dentro da perspectiva de afirmação da identidade negra e como fundamental para se alcançar os estados alterados dos participantes do Nego Fugido. No andar do meu discurso, irrompe da plateia um questionamento frio e distanciado que me alertou sobre o solo em que pisava: "Por que as pessoas precisam pintar o rosto de preto já que todos os brincantes do Nego Fugido são negros? Se Spike Lee ${ }^{1}$ visse uma apresentação do grupo, o que ele diria?"

Senti-me na responsabilidade de replicar à altura, seja por uma resposta contundente aos moldes acadêmicos, seja pelo anacronismo e pela ironia que me parecia o questionamento. Baixou o acadêmico e uma resposta foi soprada nos meus ouvidos: "se Bertolt Brecht tivesse visitado Acupe durante suas buscas incessantes por um teatro vivo e moderno, ele teria dito que o teatro didático já acontecia no Brasil antes da Alemanha, ainda no século XIX, precisamente no Recôncavo baiano com a encenação do Nego Fugido?" A comunicação se restabeleceu! Aplausos calorosos da plateia davam sinais de que

1. Spike Lee é um cineasta e ator negro estadunidense que fez fama como um diretor criativo e polêmico pela mídia especializada, sempre abordando temas raciais. O filme $A$ hora do show, lançado em 2000, enreda-nos num labirinto que escancara as tensões racistas entre negros e brancos no Estados Unidos. Ele conta a história de um diretor de televisão que remonta, de forma escrachada, os shows Blackface dos séculos XIX e XX. 
eu havia aterrissado em solos acadêmicos com segurança, todavia ainda em espaço distante da cultura afro-brasileira, legitimada pelo pensador alemão.

Alguns artistas, pesquisadores e militantes da causa do negro parecem ainda não ter compreendido os códigos e jogos simbólicos que envolvem o fazer de expressões populares da cultura brasileira. Vejamos de perto.

Depois de dois anos realizando trabalho de campo na comunidade de Acupe, retorno a São Paulo em 2017 para iniciar o doutorado. Alguns amigos brancos, negros, artistas populares, simpatizantes ou militantes do movimento negro e da cultura popular comentaram sobre a nova armadura que alguns grupos de artistas do teatro e de movimentos sociais tentam enquadrar as expressões populares da cultura. Os comentários giravam em torno da polêmica acerca do debate realizado pelo Itaú Cultural e a companhia de teatro Os Fofos Encenam, em maio de 2015, após o cancelamento da peça $A$ muIher do trem, acusada de utilizar da técnica racista blackface ${ }^{2}$. Na mesa de debate estavam o diretor da companhia, pesquisadores de teatro, professores universitários, militantes e intelectuais negros. Alguns debatedores brancos e outros brancos da plateia defenderam o uso de blackface a partir da ideia de que a máscara negra seria parte da tradição teatral ocidental - independente de uma função ideológica e discriminatória que possa ter havido na sua origem no Brasil - e alegaram que a crítica à peça seria um ato de censura. Um professor branco de teatro, convidado para compor a mesa de debate, relacionou as máscaras pretas presentes na trajetória do circo e do teatro ocidental com as máscaras pretas da cultura popular brasileira, mencionando exemplos como a Folia de Reis e o Cavalo-marinho. Esse tipo de discurso generalista, que enxerga todas as manifestações culturais do país exclusivamente sob o paradigma ocidental eurocêntrico, não contribui para um debate aprofundado sobre o tema e provavelmente tem influenciado em alguma medida os escárnios que expressões populares que usam a máscara preta vêm sofrendo recentemente. Após esse debate, manifestos vêm acontecendo em várias capitais do Brasil durante apresentações de grupos centenários de luta e resistência da cultura popular negra, acusados agora de práticas racistas.

2. Blackface é uma prática racista praticada nos Estados Unidos, por volta de 1830, por homens brancos que se pintavam de preto para ridicularizar pessoas negras, apresentando-se para grupos formados por aristocratas brancos, ganhando espaço nos cinemas e televisão posteriormente. 
O ator e bonequeiro cearense Cleydson Catarina, incomodado com os constrangimentos que a cultura popular tem sofrido, comentou comigo sobre o protesto realizado por militantes do movimento estudantil da Bahia e Minas Gerais durante uma apresentação do grupo de maracatu Rei Zumbi na 10ª Bienal da União Nacional dos Estudantes realizada em Natal no início de 2017, que relacionou a máscara preta usada pelo grupo ao blackface. Catarina relatou também protestos de repúdio ao blackface durante apresentações de um grupo de Cavalo-marinho em São Paulo.

Há várias versões acerca da origem da máscara preta das figuras do maracatu e do Cavalo-marinho, que colocam o negrume em oposição ao blackface. Catarina me disse, referindo-se aos personagens negros do teatro de bonecos:

Mateus, Bastião, João Redondo, Benedito, Catirina e outros são da mesma linhagem do Boi/Cavalo-marinho e ganham vários nomes em diferentes regiões do Nordeste. Foram esses bonecos quem me ensinaram a ser negro e a me reconhecer como negro. Colocar a máscara é reforçar o lugar de onde viemos, a nossa ancestralidade. Não colocamos a máscara para zombar da nossa ancestralidade, mas para reacender a relação com ela. (Informação verbal)

Colocando lado a lado as máscaras do maracatu do Ceará, do Cavalomarinho de Pernambuco e do Nego Fugido da Bahia, com suas singularidades e similaridades, revela-se o quanto é anacrônico, autoritário e perverso relacionar as máscaras das expressões populares da cultura ao blackface.

Façamos um retorno à mesa de debate na USP. O posicionamento de uma pessoa, aparentemente negra, em um espaço de resistência de expressões da cultura afro-brasileira dentro da universidade, revela como alguns movimentos artísticos e sociais erroneamente compreendem essas expressões de maneira reducionista, fragmentada e generalizada. Uma visão colonizadora, na maioria das vezes, influenciada por uma "trajetória perversa de manipulação" por parte da elite intelectual que pretendia encaixar a cultura popular em um modelo modernista, transformando-as em bens de consumo (PINTO, 2014). Esse acontecimento dá muito "pano pra manga". Por hora, serei obrigado a vestir meus antolhos e me ater à proposta desta comunicação, porém, sem deixar fugir a oportunidade de colocar o dedo em algumas feridas. 


\section{Nego Fugido e Brecht: ressonância no anacronismo}

No meu retorno a São Paulo, em 2017, participei de uma oficina de teatro negro, organizada por um coletivo de teatro da cidade. A maioria dos participantes se considerara negros, moradores da periferia de São Paulo. Em meio às atividades corporais da oficina, rodas de conversas versavam acerca da trajetória do negro no teatro brasileiro, o racismo sofrido pelos atores negros na dramaturgia do país e a história de luta dos movimentos artísticos negros, antigos e atuais, por reparação sociocultural. Em um desses giros de conversa, um dos participantes comentou sobre o traço áspero e afirmativo do discurso político transmitido pelo teatro negro de periferia. E o diálogo continuou: "Em um determinado momento do crescimento do teatro de temática negra, a cultura popular foi apropriada por alguns grupos a fim de propor um discurso menos áspero e mais agradável aos ouvidos do público". Outro comentário foi lançado na roda: "Precisa ter tambor e reproduzir dança de orixás pra ser considerado teatro negro? Pensar uma linguagem cênica voltada para a ancestralidade negra é reforçar estereótipos racistas".

Esses comentários se referem ao mesmo problema de dificuldade de compreender a cultura popular em si e seus significados políticos no contexto atual, despertando alguns questionamentos: Estaria o teatro popular ou o teatro negro do Brasil correndo o risco de cair num abismo de estereótipos racistas ao se aproximar da ancestralidade afro, dos seus códigos e jogos simbólicos, mesmo evitando os simulacros baratos? Tomando como referência o processo de formação artístico e sociocultural dos participantes da cultura popular afro-indígena, observada na fala de Catarina, seria possível pensar em uma epistemologia da resistência ou em uma estética quilombola a partir da teatralidade, corporalidade, visualidade e musicalidade dessas expressões culturais? Seria anacrônico refletir sobre a cultura popular e suas possibilidades cênicas a partir de territórios hegemônicos do saber acadêmico?

O teatro brasileiro sempre ignorou os aspectos cênicos e o discurso político da cultura popular. Atualmente, o teatro antropológico vem se rendendo aos aspectos teatrais da cultura popular, mas, na maioria das vezes, de forma insipiente. Por não compreender suas linguagens, códigos e jogos simbólicos, as companhias de teatro no Brasil, sobretudo alguns grupos de teatro negro, 
buscam suas referências no saber acadêmico como única forma possível de criação cênica.

$\mathrm{Na}$ oficina de teatro negro, o discurso que cruzou as rodas de conversa versava que o teatro negro está à mercê das lutas de classes e na defesa do povo marginalizado da periferia. Esse também não seria o princípio do teatro didático brechtiano? ${ }^{3}$ Permita-me mais uma vez estabelecer comparações entre o teatro didático brechtiano e o Nego Fugido para refletir sobre o discurso político da cultura popular.

No início de minha pesquisa de mestrado, minha orientadora Marianna F. Monteiro manifestava o interesse de aproximar a encenação do Nego Fugido com o teatro didático brechtiano. No entanto, a pesquisadora demonstrava certo receio:

Não seria um anacronismo pensar o Nego Fugido nas correlações com a performance e com a peça didática brechtiana? Não seria correr o risco de perder suas particularidades e sua singularidade analisar as teatralidades populares a partir de um referencial culto? Todavia, ter em vista as relações constantes e intensas entre cultura popular e erudita implica pensar seja a tradição culta do teatro ocidental, sejam as teatralidades populares, no interior dessas relações, incluindo aí, sem dúvida, a superação desse medo dos anacronismos - ainda mais (e principalmente) quando se trata de análise de fenômenos determinados intrinsecamente pela situação de "contato", como é o caso das manifestações de cultura afro-brasileira. (MONTEIRO, 2013, p. 382)

Mas o que há de Brecht no Nego Fugido e vice-versa? Para Brecht, o teatro teria que ser provocador, ousado e com um forte apelo às disputas de classe: uma arma de transformação social. Brecht não estava interessado na produção de um gênero coletivista a exemplo do teatro dramático aristotélico que exigia da arte um efeito que superasse de imediato os antagonismos de classes sociais. Ao contrário, o teatro didático reforçava as diferenças, dividindo o público.

3. O teatro denominado "épico" surgiu na Alemanha alguns anos após a Primeira Guerra Mundial, como forma experimental relativamente nova de representar, explorando discursos nitidamente narrativos e descritivos, denotando um conteúdo de profunda preocupação social. A partir de então, "o palco principiou a ter uma ação didática. O petróleo, a inflação, a guerra, as lutas sociais, a famílias, a religião [...] passaram a fazer parte do tema do teatro" (BRECHT, 2005, p. 67). 
O Nego Fugido, a exemplo do teatro didático, é um "espetáculo" da luta diária dos moradores de Acupe que, sem qualquer rodeio, escancara os dramas sociais da comunidade, dividindo opiniões e gerando conhecimento coletivo e individual. O grupo não é considerado um manifesto político, não há por parte dos participantes consciência sobre seu ativismo político e social. São pescadores, marisqueiras e seus filhos que encenam, de forma peculiar, por meio de rememoração e celebração, o processo de aquisição da liberdade dos negros escravizados no Brasil. Ao contrário do que algumas pessoas pensam sobre a máscara preta, o uso da maquiagem está longe de ser associada à exploração de uma imagem estereotipada do negro nas sociedades atuais, ridicularizando-o, enquadrando-o como pessoa ou classe inferior. A máscara do Nego Fugido escancara as diferenças como processo de luta de classes, um teatro crítico da luta diária, como o teatro proletário buscado Brecht.

Brecht visitando Acupe diria: "o Nego Fugido é um teatro de acontecimentos cotidianos que provoca estranhamento e divide as pessoas". Essa fala poderia vir da sua observação sobre a relação conflituosa e contraditória que o grupo tem com a população de Acupe, que se sente provocada pelos participantes.

A relação entre o Nego Fugido e a comunidade de Acupe sempre foi carregada de tensões. Muitos moradores não gostam do grupo, alegando que os integrantes pintam o rosto e brincam com assuntos sérios e religiosos para incomodar as pessoas. Desse modo, estabelece-se o ponto-chave do paralelismo que Monteiro (2013) buscou entre a peça didática e o Nego Fugido. Um dos aspectos da peça didática é que a encenação deve ser vivenciada e não assistida, o ator é espectador dele mesmo. A pintura e o comportamento jocoso e provocativo das figuras do Nego Fugido parecem colocar os moradores de Acupe diante de seus próprios conflitos sociais, de seus fantasmas, estimulando seu posicionamento crítico.

O teatro didático, tanto quanto o Nego Fugido, diz Monteiro (2013), não visa fixar ideias, mas modificar o método de pensar pela imitação, fora do modelo de texto dramatúrgico, livre para dirigir-se a objetos, gestos e atitudes já experimentados na vida, na realidade dos participantes ou em sua imaginação. Segundo a pesquisadora, o atuante está em estreito vínculo com sua experiência, com seu cotidiano, eliminando a possibilidade de ações 
meramente representativas, a imitação é uma elaboração crítica de sua experiência. Comportamento muitas vezes confundido, incompreendido e malbaratado pelos moradores de Acupe e pesquisadores.

A figura do capitão do mato é um exemplo dessa elaboração crítica. Ele retrata a experiência trágica da violência social que representou o regime da escravidão. É por meio dele que a comunidade de Acupe faz uma releitura, de forma jocosa, dos conflitos nas relações entre negros escravos, libertos e senhores de engenho. É uma espécie de figura/narrador, o elemento do qual irrompem todos os conflitos, meio pelo qual se dá a exposição escancarada das cenas chocantes de violência. A figura em cena revela comportamentos de uma pessoa confusa, contraditória, no limiar entre a figura de um homem mau que alude a uma memória de terror, provocando medo e desprezo das pessoas, e uma figura cômica, desengonçada, que provoca gargalhadas no público.

Retornando à discussão sobre a máscara preta da cultura popular e a ideia do blackface, tanto o capitão do mato quanto as outras figuras que representam o sistema escravista no Nego Fugido, como o rei e os militares, não usam a máscara preta (Figura 1).

Figura 1 - Capitão do mato

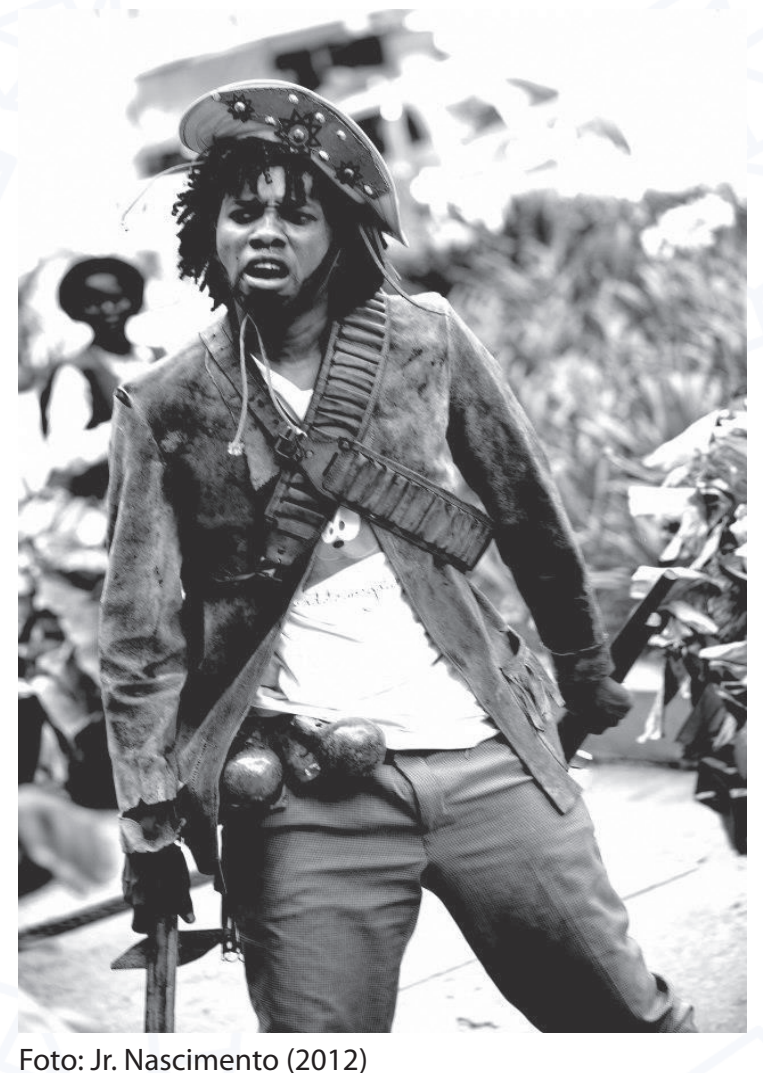


Esse comportamento contraditório do capitão do mato aparece em seus movimentos, gestos, numa irritação por uma ordem não cumprida, no andar desequilibrado, nas pernas manquejando, no corpo côncavo, nas investidas contra o público, nas ações exageradas de violência em ataques a seus pares (os caçadores), no comportamento confuso de ataques e defesas das negas, no olhar vazio, na conversa solitária, em vozes estranhas e gritos desesperados etc. O público, por sua vez, reconhece aqueles códigos corporais e contracenam com a figura do capitão do mato que, muitas vezes, é provocado, insultado e escorraçado.

Assim como no teatro didático de Brecht, em que os personagens estabelecem uma relação direta com o espectador, no Nego Fugido o público é um dos atores sociais da encenação, parte integrante da construção daquela história. As ações exageradas de violência e as brincadeiras das figuras provocam, algumas vezes, a intervenção e a invasão do público na encenação, contribuindo para a impressão de estarmos frente a uma cena malelaborada, de um teatro malfeito, que se opõe ao teatro calcado na ilusão cênica. Verdade e ficção se misturam, estendendo a encenação a outro universo de significado, numa completa estrutura de teatro brechtiano.

Encerro aqui o suposto anacronismo que empreendi para mostrar que um olhar mais atento à cultura popular revela que ela tem mais de Brecht do que de blackface.

Vale ressaltar que essa tentativa de estabelecer diálogo entre o saber "tradicional" da cultura popular e o saber hegemônico contemporâneo das artes cênicas, aqui representado por Bertolt Brecht, também está presente no terceiro capítulo da minha dissertação de mestrado "Prefácio entre o Nego Fugido e as linguagens teatrais" (PINTO, 2014), no qual traço comparações entre a expressão cultural e pensamentos ou procedimentos metodológicos de autores como Antonin Artaud, Eugenio Barba, Bertolt Brecht, Jerzy Grotowski - que em alguns aspectos de suas pesquisas aparecem em oposição - para refletir sobre os elementos teatrais, musicais, corporais e visuais do grupo. No entanto, o Nego Fugido, tal qual ocorre em Acupe, dificilmente poderia ser considerado um espetáculo no sentido tradicional desse termo. É realizado por pescadores e marisqueiras, por não atores, pessoas que nunca foram a um teatro e não vivem essa expressão como uma manifestação de teatro ou 
mesmo atribuem qualquer sentido artístico a ela (MONTEIRO, 2013). Longe de tentar enquadrar a expressão popular a um modelo cênico, a proposta do capítulo da dissertação é ampliar as possibilidades de reflexão acerca de sua construção simbólica e estética. A originalidade do Nego Fugido está na pluralidade de sua linguagem, que gera formas culturais híbridas: em cada canto, dança e música se observa a incorporação de elementos múltiplos, resultantes de processos históricos e sociais. Lanço a hipótese de que as lembranças traumáticas de luta, revolta e resistência da população escrava do Recôncavo baiano são os elementos norteadores do grupo que, a partir de uma reconstrução do passado, revela o quadro das tensões e dos problemas sociais, culturais e políticos atuais de Acupe. Uma forma de epistemologia da resistência que gera códigos, jogos simbólicos e elementos teatrais que nos possibilitam refletir sobre perspectivas cênicas pautadas em questões socioculturais e políticas.

\section{Referências bibliográficas}

BRECHT, B. Estudos sobre teatro. Rio de Janeiro: Nova Fronteira, 2005.

MONTEIRO, M. Nego Fugido, teatro didático e "agitprop". In: DAWSEY, J. C. et al.

Antropologia e performance: ensaios Napedra. São Paulo: Terceiro Nome, 2013. PINTO, M. S. Prefácio entre o Nego Fugido e as linguagens teatrais. In: Nego

Fugido: o teatro das aparições. 2014. Dissertação (Mestrado em Artes) - Instituto de Artes, Universidade Estadual Paulista “Júlio de Mesquisa Filho”, São Paulo, 2014.

Recebido em 22/04/2017

Aprovado em 06/06/2017

Publicado em 05/09/2017 